\title{
Lugdulysin of Staphylococcus lugdunensis, a metalloprotease that inhibits and disrupts protein biofilm of Staphylococcus aureus
}

\author{
Juan Pinheiro Oliveira Martinez \\ Instituto Federal de Educação, Ciência e Tecnologia do Rio de Janeiro \\ Leonardo Vazquez \\ Universidade Federal do Rio de Janeiro \\ Matheus Mikio Takeyama \\ Instituto Federal de Educação, Ciência e Tecnologia do Rio de Janeiro \\ Tarcizio José Santos Filho \\ Universidade Federal do Rio de Janeiro \\ Fernanda Sampaio Cavalcante \\ Universidade Federal do Rio de Janeiro \\ Lorrayne Cardoso Guimarães \\ Universidade Federal do Rio de Janeiro

\section{Eliezer Menezes Pereira} \\ Instituto Federal de Educação, Ciência e Tecnologia do Rio de Janeiro \\ Katia Regina Netto Dos Santos ( $\nabla$ santoskm@micro.ufrj.br) \\ Universidade Federal do Rio de Janeiro
}

\section{Research Article}

Keywords: S. lugdunensis, lugdulysin metalloprotease, S. aureus biofilm

Posted Date: July 13th, 2021

DOI: https://doi.org/10.21203/rs.3.rs-690663/v1

License: (c) (i) This work is licensed under a Creative Commons Attribution 4.0 International License. Read Full License 


\section{Abstract \\ Background}

Staphylococcus lugdunensis is a commensal skin microorganism that, unlike other coagulase-negative staphylococci, presents increasing clinical importance. This species yields a metalloprotease called lugdulysin that may contribute to its higher degree of virulence. This study aimed to determine the biochemical characterization of the lugdulysin produced by $S$. lugdunensis clinical isolates and investigate its effect on the formation and disruption of biofilm of Staphylococcus aureus isolates. The protease was isolated and characterized for its optimal $\mathrm{pH}$ and temperature, activity in the presence of inhibitors and enzymatic kinetics. The influence of metal cofactor supplementation on proteolysis was also evaluated, with and without inhibitors. Finally, the protease capacity to inhibit and disrupt biofilms of different $S$. aureus lineages and biofilm matrix was analyzed.

\section{Results}

The protease optimal $\mathrm{pH}$ and temperature were 7.0 and $37^{\circ} \mathrm{C}$, respectively. EDTA inhibited the protease, and the activity was not recovered by divalent ion supplementation. In addition, divalent ions did not change enzymatic activity without inhibitors, which was stable for up to 3 hours. Its structure was determined via homology modelling. The protease significantly inhibited the formation and disrupted established biofilms of $S$. aureus isolates with protein biofilm.

\section{Conclusions}

This study confirmed features of the lugdulysin metalloprotease and showed that this $S$. lugdunensis virulence factor may be a new competition mechanism and/or modulation of the staphylococcal biofilm.

\section{Background}

Coagulase-negative staphylococci (CoNS) are usually found in the microbiota of the skin and mucosa and has become an opportunistic pathogen due to their ability to colonize invasive medical devices, causing bloodstream infection [1]. Although most CoNS tend to have more latent pathogenicity, Staphylococcus lugdunensis is an exception with a higher virulence degree $[2,3]$. This pathogen is the second leading cause of CoNS endocarditis [4, 5], and it is well-known for its pathogenicity in bone and joint infections [2, 6, 7]. Staphylococcus Iugdunensis can adhere to cell-surface proteins such as fibronectin and fibrinogen and produce toxins, likewise $S$. aureus [8-10]. Moreover, this species also carries $\operatorname{agr}[11], f b /[9,12], \operatorname{at} / L[13], v w b /[14]$ and s/ush $[9,15]$ genes that encode factors capable of contributing to its virulence.

In vitro studies have identified proteolytic factors that may explain clinical manifestations of staphylococcal infections [7, 16]. Lately, Argemi et al. [7] described a metalloprotease produced by S. lugdunensis clinical isolates named lugdulysin. Lugdulysin, is a hyicolysin-like protease, a metalloprotease found in Staphylococcus hyicus associated with osteoarticular infections $[7,17]$. The involvement of metalloproteases in human diseases occurs due to their ability to remodel the extracellular matrix, as observed in osteomyelitis, tumor invasion, metastasis, and vascular inflammatory diseases [18-20]. Many studies support the hypothesis that proteases could play a 
role in the formation and stability of microbial biofilms from many species [21, 22]. In $S$. aureus isolates, these enzymes can limit the growth and detachment of biofilm by sarA-and agr-mediated mechanism, respectively [22, 23]. Proteases are also necessary to induce Staphylococcus epidermidis biofilm formation by processing the Aap protein [24]. Additionally, Connely et al. [25] have demonstrated that Bacillus subtilis lacking extracellular proteases could not produce biofilms [25]. In all cases, the biofilm matrixes were mainly composed of proteins like occurs in the biofilm of $S$. lugdunensis isolates $[9,26,27]$.

Despite the initial characterization of lugdulysin carried out by Argemi et al. [7], its chemical and structural characteristics remain unknown. Hence, this study aimed to elucidate biochemical aspects of lugdulysin and investigate its influence on the formation and disruption of biofilm from $S$. aureus isolates belonged to different lineages and presenting different biofilm matrices.

\section{Results}

\section{Protease purification and expression identification}

Bands of 50kDa obtained after electrophoresis were excised from PAGE and MALDI-TOF MS and the search for homologous sequence indicated that it corresponded to putative neutral metalloprotease produced by $S$. lugdunensis (Table 1). The subcellular localization prediction by Gpos-mPLoc and PSortB describes the sequence as extracellular (data not shown). The protein has a pre-protein region with yet unknown function [7]. The secondary structure, according to I-TASSER, shows that the protein is composed of $64.73 \%$ in loop, $13.27 \%$ in sheet and $21.97 \%$ in helix, with no transmembrane domains (Fig. 1). The protease sequence was also analyzed for its genetic ontology (Fig. 2). Due to the presence of the HEXXH domain, the enzyme requires a zinc molecule in its catalytic site to be active. The isoelectric point of the enzyme is 4.99 . Therefore, the enzyme is possibly active whilst negatively charged. 
Table 1

Identification of the metalloprotease using purified secreted proteins from Staphylococcus lugdunensis supernatant by searching for homologous sequences with the Mascot software online database

\begin{tabular}{|c|c|c|c|}
\hline Score & $\begin{array}{l}\text { Mass } \\
(\mathrm{kDa})\end{array}$ & Matches & Description \\
\hline 385 & 23972 & 13 & $\begin{array}{l}\text { Chain } A \text {, use of the neutron diffraction } \mathrm{HD} \text { exchange technique to determine } \\
\text { the conformational dynamics of trypsin }\end{array}$ \\
\hline 192 & 26093 & 5 & Chain A, bovine trypsin complexed with Rpr131247 \\
\hline 212 & 66198 & 16 & Keratin 1 [Homo sapiens] \\
\hline 109 & 66230 & 6 & Keratin, type II cytoskeletal 2 epidermal [Pan troglotydes] \\
\hline 173 & 62320 & 8 & Cytokeratin 9 [Homo sapiens] \\
\hline 162 & 62932 & 7 & Predicted: keratin, type I cytoskeletal 10 isoform X 1 [Pan troglotydes] \\
\hline 53 & 48667 & 2 & Predicted: low quality protein: polymerase-2-like [Thamnophis sirtalis] \\
\hline 52 & 50020 & 1 & Neutral metalloprotease [Staphylococcus lugdunensis] \\
\hline 46 & 38050 & 1 & $\begin{array}{l}\text { Hypothetical protein [uncultured Microgenomates bacterium } \\
\text { Rifle_16ft_4_minimus_37633] }\end{array}$ \\
\hline 42 & 32424 & 2 & Predicted: trypsin alpha-like [Stomoxys calcitrans] \\
\hline 37 & 31095 & 1 & Hypothetical protein [Paenibacillus sp. Root52] \\
\hline 35 & 24467 & 2 & $\begin{array}{l}\text { Chain E, Crystal structures of rat anionic trypsin complexed with the protein } \\
\text { inhibitors Appi and Bpti }\end{array}$ \\
\hline 28 & 31710 & 1 & Predicted: low quality protein: trypsin II-P29-like [Haliaeetus albicilla] \\
\hline 22 & 53182 & 1 & Predicted: uncharacterized protein LOC105797379 [Gossypium raimondi]] \\
\hline 21 & 28005 & 2 & CG8299 [Drosophila melanogaster] \\
\hline 17 & 206260 & 3 & Zinc finger Isd1 subclass family protein [Tetrahymena thermophila SB210] \\
\hline
\end{tabular}

Staphylococcus lugdunensis metalloprotease is highlighted in bold with the respective match, score, and its predicted mass $(\mathrm{kDa})$. Other proteins with more matches are common contaminants inherent to the methodology.

\section{Protease biochemical characterization}

The proteolytic enzyme activity from 546s S. lugdunensis isolate identified by mass spectrometry was measured by a colorimetric biochemical assay using azocasein as substrate. The EDTA caused a significant reduction in proteolytic activity, with a statistically significant decrease $(p<0.01)$ compared to the activity without inhibition (Fig. 3A). There was no recovery in activity with any metals supplemented after EDTA inhibition (Fig. 3B). The figure shows activity with $5 \mathrm{mM}$ EDTA and no metals added as a control. Then, $1 \mathrm{mM}$ calcium, magnesium, zinc, and manganese were added in the other bars showing no significant change between themselves and control. Metal saturation in the medium was not able to recover the enzymatic activity of lugdulysin. Not only was there no recovery of activity after EDTA inhibition by metal ion supplementation, as there was no significant change in proteolytic activity with different metal supplementation without inhibition. In Fig. 3C, the first bar shows unsupplemented protease activity, while the other bars show the same protease supplemented with $1 \mathrm{mM}$ 
calcium, magnesium, zinc, and manganese. There is no significant difference between unsupplemented and supplemented protease activity. A negligible activity level was observed from pH 2.0 to 4.0, with a slight increase in activity from pH 6.0 and reaching peak activity at pH 7.0, reducing at pH 8.0 (Fig. 3D).

- Regarding the influence of temperature (Fig. 3E), it is notable that the highest proteolytic activity are shown between $37^{\circ} \mathrm{C}$ and $40^{\circ} \mathrm{C}$, with temperatures above or below these values exhibiting considerable decrease. The proteolytic activity begins immediately, with absorbance above control in 10 minutes of reaction (Fig. 3F). The activity reached a plateau around one and a half hour, with no significant increase up to 3 hours of activity. The determination of $\mathrm{K}_{\mathrm{m}}$ and $\mathrm{V}_{\max }$ was obtained with the substrate saturation in the enzymatic activity. The values obtained from a non-linear regression, are shown in Figs. $3 \mathrm{G}$ and $3 \mathrm{H}$.

\section{Disruption and inhibition of biofilm production by proteases}

Trypsin can determine the biofilm composition between protein and non-protein biofilm, as it degrades specifically the proteins present in it. Figure 4A shows the effect of trypsin or lugdulysin on biofilm formation in six staphylococcal isolates. Trypsin inhibited the formation of more than $70 \%$ of the $S$. lugdunensis protein biofilm and between $60 \%$ and $70 \%$ of the $S$. aureus protein biofilm. Lugdulysin metalloprotease showed a reduction above $50 \%$ for $S$. aureus protein biofilm and between $20 \%$ and $40 \%$ for S. Iugdunensis biofilm. Less than $10 \%$ inhibition in $S$. aureus polysaccharide biofilm was observed.

Finally, the protease disruptive potential in pre-formed biofilm was evaluated. Trypsin disrupted between $40 \%$ and $50 \%$ of $S$. aureus protein biofilm and more than $70 \%$ of S. Iugdunensis biofilm. Lugdulysin promoted a reduction from $40-50 \%$ in $S$. aureus protein biofilm, similar to trypsin, but no biofilm reduction was observed for $S$. lugdunensis. Contrastingly, the impact of lugdulysin in S. Iugdunensis biofilm was shallow compared to trypsin ( $p$ $<0.0001)$. Non-protein matrix biofilm isolates did not shown any reduction with the addition of trypsin or lugdulysin (Fig. 4B).

\section{Discussion}

Lugdulysin could be involved in S. lugdunensis pathogenicity according to previous findings. However, its fundamental biochemical properties had not yet been determined. Based on the genomic annotation of $S$. lugdunensis, only one metalloprotease presents a molecular weight of $37 \mathrm{kDa}$ produced by this species, as briefly proposed by Argemi et al. [7]. The present study supports this finding, where the extracellular proteins were concentrated, and the proteolytic activity was confirmed by degradation of azocasein. This assay was also used to investigate the influence of EDTA, a metalloprotease inhibitor that extinguished the enzyme's proteolytic activity.

Furthermore, the similarity of the protease to the previously characterized enzyme (MEROPS Accession number MER0001182) was confirmed by mass-spectrometry peptide sequencing. As there was no previous characterization of this enzyme, various functional properties, such as its activity lifespan, optimal pH and temperature were investigated, the influence of inhibitors and supplementation with metallic ions. We further analyzed different functional properties and through in silico analysis, providing information regarding cell location, isoelectric point, putative cleavage preference and the 3D structure of lugdulysin. Zinc-ion binding sites were identified, which was already expected by the presence of the HEXXH domain. Predict Protein server identified putative metalloendopeptidase activity, cleaving L-amino acid-rich peptides at inner parts of peptides 
instead of amino or carboxy-terminal [28]. Given the presence of a signal peptide, the protease is likely secreted, as previously suggested by Argemi [7].

In the present study, EDTA significantly reduced the proteolytic activity, confirming the lugdulysin as a metalloprotease $[29,30]$. In our attempt to recover its activity after inhibition, there was no observable recovery after adding $\mathrm{Ca}^{2+}, \mathrm{Mg}^{2+}, \mathrm{Zn}^{2+}$ or $\mathrm{Mn}^{2+}$. It is possible that its structure is affected by the metal removal, which could prevent the recovery of the proteolytic activity [31]. It is known that metalloproteases respond diversely to different metallic ions. The response of the lugdulysin to ions is similar to aureolysin, another staphylococcal metalloprotease produced by the $S$. aureus [32]. For both metalloproteases, after inactivation with EDTA, ions were also unable to restore the protease activity. On the other hand, hyicolysin, a metalloprotease of $S$. hyicus, has its activity entirely recovered by adding zinc and cobalt, and partially restored with $\mathrm{Mg}^{2+}, \mathrm{Ca}^{2+}$ and $\mathrm{Cu}^{2+}$ [17]. These data indicate a close relationship with $S$. aureus, as already shown among other features presented by both species, such as adhesins and hemolysins [9].

The biochemical characterization indicated that, despite its structural similarity with hyicolysin [7], lugdulysin shares more biochemical similarities with aureolysin. For instance, the optimum $\mathrm{pH}$ and temperature of hyicolysin are 7.4 to 7.9 and $55^{\circ} \mathrm{C}$, respectively [17], while for lugdulysin and aureolysin is 7.0 and $37^{\circ} \mathrm{C}$. Indeed, whilst the clinical relevance of hyicolysin remains unclear, it is known that aureolysin play an essential role in the pathogenesis of $S$. aureus infections. This metalloprotease can modulate the pathogenesis of osteomyelitis by triggering alterations in bone turnover [16], promotes the escape of immune response, inhibiting the complement system by degradation of C3 component [33] and cleaves staphylococcal surface-associated proteins allowing the transition from an adherent to an invasive phenotype [34]. Thus, the biochemical properties of lugdulysin, like aureolysin, could be related to the emergence of $S$. Iugdunensis as pathogenic bacteria implicated in severe infections, especially endocarditis and osteoarticular infections [18].

The effect of proteases against biofilms of $S$. aureus is already well established in the literature [35, 36]. Here, lugdulysin significantly reduced the $S$. aureus pre-formed protein biofilm, similar to trypsin, inhibiting the production of protein biofilm by $S$. aureus. Diversely, the same outcome did not occur in $S$. lugdunensis isolates. To this species, lugdulysin did not affect the pre-formed biofilm, causing only a slight inhibition in biofilm production. These results are surprising because not even the biofilm of $S$. aureus is so resistant to own metalloprotease as the biofilm of $S$. Iugdunensis appears to be resistant to lugdulysin. In vitro studies demonstrated that aureolysin significantly disrupt the $S$. aureus pre-formed protein biofilm [22, 36]. Even more, Abraham \& Jeferson [36] found that the inactivation of the aureolysin gene augments $S$. aureus biofilm production. Nonetheless, some species produce proteases that can protect and modulate the biofilm formation whereas attack biofilms of bacteria from other species $[37,38]$. However, to our knowledge, there are no reports to date of any staphylococcal protease that simultaneously acts to protect the biofilm of the species that produces it and causes damage to the biofilm of another species. The resistance of the S. lugdunensis protein biofilm to its protease could demonstrate a possible new mechanism that may generate a competitive advantage among staphylococci.

Our study presents some limitations. First, biochemical studies are needed for a better comprehension of lugdulysin characteristics, such as substrate specificity. Second, we have not established the mechanism by which lugdulysin affects $S$. aureus biofilm. It remains unclear whether it degrades the protein matrix or acts on 
proteins involved in biofilm gene expression. Also, the effect of lugdulisin on S. aureus was only evaluated in vitro, which limits the understanding of the role of this metalloprotease as a virulence factor.

\section{Conclusions}

This report identified optimal conditions of function and stability of the lugdulysin produced by S. Iugdunensis isolates from human clinical specimens. Moreover, we showed the striking effect of this protease on the formation and dispersion of biofilm from different $S$. aureus isolates, a pathogen of significant clinical relevance which biofilm has been associated with antimicrobial resistance and invasive medical devices related infections. These preliminary findings show that lugdulysin may be a new mechanism of competition and/or modulation of the staphylococcal biofilm.

\section{Methods}

\section{Bacterial isolates}

Previous published bacterial isolates of $S$. lugdunensis (541s and 546s) and $S$. aureus (63a, 1636a, 1176a and 1348a) $[9,39,40]$ were selected for the study. These isolates belonged to the Laboratory of Hospital Infection collection at the Federal University of Rio de Janeiro. They presented distinct genotypic profiles determined by the PFGE technique. In addition, the biofilm characteristics and biochemical composition were also determined previously, according to Ferreira et al. [41] (Table 2).

Table 2

Characteristics of the staphylococci isolates used in the present study

\begin{tabular}{|c|c|c|c|c|c|c|c|}
\hline Species & $\begin{array}{l}\text { Isolate } \\
\text { number }\end{array}$ & $\begin{array}{l}\text { Clinical } \\
\text { specimen }\end{array}$ & $\begin{array}{l}\text { Methicillin } \\
\text { susceptibility }\end{array}$ & $\begin{array}{l}\text { Clonality/ } \\
\text { ST }\end{array}$ & $\begin{array}{l}\text { Biofilm } \\
\text { matrix } \\
\text { composition }\end{array}$ & $\begin{array}{l}\text { Biofilm } \\
\text { production }\end{array}$ & Reference \\
\hline \multirow[t]{4}{*}{ S. aureus } & $63 a$ & nares & resistant & $\mathrm{BEC} / 239$ & PRT + PSC & Strong & [40] \\
\hline & $1636 a$ & blood & resistant & USA100/5 & PRT + eDNA & Strong & [39] \\
\hline & $1176 a$ & urine & sensitive & USA800/5 & PSC & Strong & [40] \\
\hline & $1348 a$ & blood & sensitive & USA400/1 & PSC & Strong & [40] \\
\hline \multirow{2}{*}{$\begin{array}{l}\text { S. } \\
\text { lugdunensis }\end{array}$} & $541 \mathrm{~s}$ & blood & sensitive & A & PRT & Strong & [9] \\
\hline & $546 s$ & blood & sensitive & $A$ & PRT & Strong & [9] \\
\hline
\end{tabular}

\section{Protease isolation}

Colonies of S. Iugdunensis 546s isolate grown on Tripic Soy Agar (TSA) (Becton Dickinson, USA) were transferred to $1 \mathrm{~L}$ Tryptic Soy Broth (TSB) (Becton Dickinson) and subjected to overnight incubation at $37^{\circ} \mathrm{C}$ under $200 \mathrm{rpm}$. After growth, isolates were centrifuged for 25 minutes at $7000 \times \mathrm{xg}\left(4^{\circ} \mathrm{C}\right)$. The supernatant with the protease was subjected to vacuum pump filtration (GAST - IDEX Health \& Science, LLC, USA) with a $0.22 \mu$ m membrane (Sartorius Stedim Biotech SA Frankfurt., Germany). The recovered supernatant was then subjected to a tangential 
flow filtration procedure (Millipore Lab Scale TFF System, Millipore, Mass., USA) using an initial volume of $1 \mathrm{~L}$ and reducing to approximately $30 \mathrm{~mL}$ for approximately 4 hours. The supernatant was concentrated using a $50 \mathrm{kDa}$ ultrafiltration membrane (Pellicon XL 50 - Millipore), and lyophilized. The dry weight was determined and the material was resolubilized in Tris- $\mathrm{HCl} 20 \mathrm{mM} \mathrm{pH} \mathrm{7.0.}$

\section{Protein profile analysis}

The concentrated supernatant was analyzed using SDS-PAGE (Sodium Dodecyl Sulphate Polyacrylamide Gel Electrophoresis) with 15\% acrylamide according to Laemli [42] and stained according to Neuhoff [43]. The coomassie-stained gel was then destained and submitted to in-gel digestion using trypsin $20 \mu \mathrm{g} / \mathrm{mL}$ (SigmaAldrich), adapted from Shevchenko [44]. The trypsinized peptides were analyzed in a MALDI-TOF/TOF type mass spectrometer (Microflex LT, Bruker, USA) [44]. Mascot Distiller software was used to analyze the processed bands for MALDI-TOF/TOF analysis and raw data (Matrix Science, version 2.2.1.0). Protein identification was performed by searching for homologous sequences in online Mascot software (Table 2). In silico analysis of the metalloprotease was performed with the sequence deposited by previous characterization [7], available at UniProt under the accession number A0A133QCC8. Proteases domain and other biochemical characteristics were proposed using the automated Predict Protein (https://predictprotein.org/), using a database of up-to-date public sequences, performing alignments, and predicting protein function and structure [45]. Prediction of cell location was performed using automated domain service, while analysis of other biochemical characteristics was performed using the automated service to predict subcellular localization of Cell-PLoc proteins, Gpos-mPLoc, for prediction specifically in Gram-Positive bacteria [46]. Those data correlated to data obtained in PSortB, which performed the same analysis [47]. The putative structure was obtained via homology modeling using the protein prediction webserver I-TASSER [48].

\section{Protease biochemical characterization}

To determine proteolytic activity, a colorimetric method determined by Lei and coworkers [29] was carried out, with adaptations. As a positive control, trypsin (Sigma-Aldrich) (initial concentration $20 \mu \mathrm{g} / \mathrm{mL}$ ) was used, and, for the negative control, the protease received immediate addition of $10 \%$ trichloroacetic acid (TCA). The activity units (U) that were determined as the variation of $440 \mathrm{~nm}$ absorbance per $\mathrm{mg}$ of protein per hour. This protocol was used to evaluate the effect of inhibitors on protease, with the addition of 5mM EDTA in the reaction [47]. Various divalent metals were supplemented in the reaction medium to evaluate the metal influence on proteolytic activity, following proteolytic activity method [29] and adding $1 \mu \mathrm{L}$ of $1 \mathrm{M}$ metallic salt. In this study, Calcium Chloride (VETEC, Brazil), Zinc Chloride (Isofar, Brazil), Manganese Chloride (Carlo Erba, Italy) and Magnesium Chloride (Sigma-Aldrich, USA) were used. To assess the recovery of proteolytic activity, the azocasein method [29] was carried out with EDTA-inhibited enzyme. Various metallic salts were supplemented in the reaction medium to overcome the EDTA chelating potential following the abovementioned method. The optimum $\mathrm{pH}$ was determined with various buffers with different $\mathrm{pH}$ were used. The selected buffers were $\mathrm{pH} 2.0 \mathrm{KCl}-\mathrm{HCl}$ buffer, $\mathrm{pH} 4.0$ acetic acid/sodium acetate buffer, $\mathrm{pH} 6.0$ and $\mathrm{pH} 8.0$ phosphate buffer, $20 \mathrm{mM}$. The method was conducted as per the previously described method [29] with $37^{\circ} \mathrm{C}$ incubation. To evaluate optimum enzyme operating temperature, the azocasein method [29] was performed at pHk9l 7.0 in different temperatures: $10^{\circ} \mathrm{C}, 20^{\circ} \mathrm{C}, 30^{\circ} \mathrm{C}, 40^{\circ} \mathrm{C}, 50^{\circ} \mathrm{C}, 60^{\circ} \mathrm{C}, 90^{\circ} \mathrm{C}$. The rate of substrate cleavage was determined with a substrate serial dilution curve following, for 15 minutes. The concentrations of azocasein used were: $0.04,0.08,0.16,0.32,0.640$ and $1.28 \mathrm{mg} / \mathrm{mL}$. Michaelis-Menten and Lineweaver-Burk curves were plotted based on these data to determine $\mathrm{Km}$ and $\mathrm{V}_{\max }$ for azocasein.

\section{Protease influence on biofilm formation}


Metalloprotease influence on biofilm formation was analyzed by the quantitative micromethod to evaluate biofilm production described by Stepanovic [49] with modifications. Twenty microliters of a bacterial suspension in sterile distilled water corresponding to the $0.5 \mathrm{McF}$ arland standard were added in triplicate to the wells containing $180 \mu \mathrm{l}$ of tryptic soy broth, TSB (Becton, Dickinson and Company; Sparks, MD, USA), supplemented with $1 \%$ glucose (Isofar; Duque de Caxias, RJ, Brazil). Finally, $15 \mu \mathrm{L}$ of freeze-dried protease diluted in PBS $(20 \mu \mathrm{g} / \mathrm{mL})$ were added in triplicate for each. The plates were incubated at $37^{\circ} \mathrm{C}$ for $24 \mathrm{~h}$. Then, wells were washed twice with sterile PBS buffer ( $\mathrm{pH} 7.2)$, dried for $1 \mathrm{~h}$ at $60^{\circ} \mathrm{C}$, and stained with $200 \mu \mathrm{L}$ of a0.1\% safranin solution (w/v, in water) for 15 min. After, wells were washed twice again, and $200 \mu \mathrm{L}$ of a $95 \%$ ethanol solution was added. Absorbance (OD492nm) was read after $30 \mathrm{~min}$ of incubation at room temperature. The culture medium without bacterial inoculum was used as a negative control and trypsin $(20 \mu \mathrm{g} / \mathrm{mL})$ was used as the positive control. All experiments were performed in triplicate at 3 independent times.

\section{Protease influence on pre-formed biofilm}

To observe the protease influence in pre-formed biofilm, the biofilm formation was initially performed on 96-well plate as previously described [49] with modifications. After the bacterial suspension is added to the wells and the microplate were incubated at $37^{\circ} \mathrm{C}$ for $24 \mathrm{~h}$. The medium was discarded, and three washing steps with $200 \mu \mathrm{L}$ sterile PBS buffer, pH 7.2 (Laborclin, Brazil) were performed to remove unbound cells. Then, $135 \mu \mathrm{L}$ of PBS 100 $\mathrm{mM} \mathrm{pH} 7.5$ and $15 \mu \mathrm{L}$ of freeze-dried protease $(20 \mu \mathrm{g} / \mathrm{mL})$ were added in triplicate for each isolate, and the $96-w e l l$ plate was submitted to a second incubation at $37^{\circ} \mathrm{C}$ for $1=\mathrm{h}$. After, the medium was discarded, another wash was performed with $200 \mu \mathrm{L}$ PBS to remove unbound cells, followed by incubation at $60^{\circ} \mathrm{C}$ for 1 hour, and wells were stained with $200 \mu \mathrm{L}$ of a $0.1 \%$ safranin solution (w/v, in water) for $15 \mathrm{~min}$. After, wells were washed twice again, and $200 \mu \mathrm{L}$ of a $95 \%$ ethanol solution was added. Absorbance (OD492nm) was read after 30 min of incubation at room temperature. The culture medium without bacterial inoculum was used as a negative control, and trypsin (20 $\mu \mathrm{g} / \mathrm{mL}$ ) was used as the positive control. All experiments were also performed in triplicate at three independent times.

\section{Declarations}

\section{Ethics approval and consent to participate}

Not applicable

\section{Consent for publication}

Not applicable

\section{Availability of data and materials}

The datasets used and analyzed during the current study are available from the corresponding author on reasonable request.

\section{Competing interests}

The authors declare that they have no competing interests

\section{Funding}


This study was supported by Brazilian grants from Fundação Carlos Chagas Filho de Amparo à Pesquisa do Estado do Rio de Janeiro (FAPERJ, grants E-26/202.592/2019, E26/010.001463/2019, E-26/010.001280/2016 and E-26/010.001280/2016), Conselho Nacional de Desenvolvimento Científico e Tecnológico (CNPq, grant 301846/2017-0), Coordenação de Aperfeiçoamento Pessoal de Nível Superior - Brasil (CAPES) - Finance Code 001, and Fundação Oswaldo Cruz (FIOCRUZ).

\section{Acknowledgements}

The authors are grateful to Julio Alberto Mignaco for granting access to equipment that enabled this research.

\section{References}

1. Becker K, Heilmann C, Peters G. Coagulase-Negative Staphylococci. Clin Microbiol Rev. 2014;27:870-926. doi:10.1128/CMR.00109-13.

2. Frank KL, del Pozo JL, Patel R. From clinical microbiology to infection pathogenesis: how daring to be different works for Staphylococcus lugdunensis. Clin Microbiol Rev. 2008;21:111-33. doi:10.1128/CMR.00036-07.

3. Nesher L, Tarrand J, Chemaly RF, Rolston KV. Staphylococcus lugdunensis infections, filling in the gaps: a 3year, retrospective review from a comprehensive cancer center. Support Care Cancer. 2017;25:1063-9. doi:10.1007/s00520-016-3493-7.

4. Petti CA, Simmon KE, Miro JM, Hoen B, Marco F, Chu VH, et al. Genotypic diversity of coagulase-negative staphylococci causing endocarditis: a global perspective. J Clin Microbiol. 2008;46:1780-4.

5. Jones RM, Jackson MA, Ong C, Lofland GK. Endocarditis caused by Staphylococcus lugdunensis. Pediatr Infect Dis J. 2002;21:265-8.

6. Douiri N, Hansmann Y, Lefebvre N, Riegel P, Martin M, Baldeyrou M, et al. Staphylococcus lugdunensis: a virulent pathogen causing bone and joint infections. Clin Microbiol Infect. 2016;22:747-8.

7. Argemi X, Prévost G, Riegel P, Keller D, Meyer N, Baldeyrou M, et al. VISLISI trial, a prospective clinical study allowing identification of a new metalloprotease and putative virulence factor from Staphylococcus lugdunensis. Clin Microbiol Infect. 2017;23:334.e1-334.e8.

8. Lourtet-Hascoët J, Bicart-See A, Félicé MP, Giordano G, Bonnet E. Staphylococcus lugdunensis, a serious pathogen in periprosthetic joint infections: comparison to Staphylococcus aureus and Staphylococcus epidermidis. Int J Infect Dis. 2016;51:56-61.

9. Pereira EM, Teixeira CAA, Alvarenga ALM, Schuenck RP, Giambiagi-deMarval M, Holandino C, et al. A Brazilian lineage of Staphylococcus lugdunensis presenting rough colony morphology may adhere to and invade lung epithelial cells. J Med Microbiol. 2012;61 Pt 4:463-9.

10. Lambe DW, Ferguson KP, Keplinger JL, Gemmell CG, Kalbfleisch JH. Pathogenicity of Staphylococcus lugdunensis, Staphylococcus schleiferi, and three other coagulase-negative staphylococci in a mouse model and possible virulence factors. Can J Microbiol. 1990;36:455-63.

11. Vandenesch F, Projan SJ, Kreiswirth B, Etienne J, Novick RP. Agr-related sequences in Staphylococcus lugdunensis. FEMS Microbiol Lett. 1993;111:115-22. doi:10.1111/j.1574-6968.1993.tb06370.x.

12. Mitchell J, Tristan A, Foster TJ. Characterization of the fibrinogen-binding surface protein Fbl of Staphylococcus lugdunensis. Microbiol Read Engl. 2004;150 Pt 11:3831-41. 
13. Bourgeois I, Camiade E, Biswas R, Courtin P, Gibert L, Götz F, et al. Characterization of AtlL, a bifunctional autolysin of Staphylococcus lugdunensis with $\mathrm{N}$-acetylglucosaminidase and $\mathrm{N}$-acetylmuramoyl-I-alanine amidase activities. FEMS Microbiol Lett. 2009;290:105-13.

14. Nilsson M, Bjerketorp J, Wiebensjö A, Ljungh A, Frykberg L, Guss B. A von Willebrand factor-binding protein from Staphylococcus lugdunensis. FEMS Microbiol Lett. 2004;234:155-61.

15. Donvito B, Etienne J, Denoroy L, Greenland T, Benito Y, Vandenesch F. Synergistic hemolytic activity of Staphylococcus lugdunensis is mediated by three peptides encoded by a non-agr genetic locus. Infect Immun. 1997;65:95-100.

16. Cassat JE, Hammer ND, Campbell JP, Benson MA, Perrien DS, Mrak LN, et al. A secreted bacterial protease tailors the Staphylococcus aureus virulence repertoire to modulate bone remodeling during osteomyelitis. Cell Host Microbe. 2013;13:759-72.

17. Ayora S, Götz F. Genetic and biochemical properties of an extracellular neutral metalloprotease from Staphylococcus hyicus subsp. hyicus. Mol Gen Genet MGG. 1994;242:421-30.

18. Argemi X, Hansmann Y, Riegel P, Prévost G. Is Staphylococcus lugdunensis Significant in Clinical Samples? J Clin Microbiol. 2017;55:3167-74.

19. Malemud CJ. Matrix metalloproteinases (MMPs) in health and disease: an overview. Front Biosci J Virtual Libr. 2006;11:1696-701.

20. Ortega N, Behonick D, Stickens D, Werb Z. How proteases regulate bone morphogenesis. Ann N Y Acad Sci. 2003;995:109-16.

21. Carniol K, Gilmore MS. Signal transduction, quorum-sensing, and extracellular protease activity in Enterococcus faecalis biofilm formation. J Bacteriol. 2004;186:8161-3.

22. Loughran AJ, Atwood DN, Anthony AC, Harik NS, Spencer HJ, Beenken KE, et al. Impact of individual extracellular proteases on Staphylococcus aureus biofilm formation in diverse clinical isolates and their isogenic sarA mutants. MicrobiologyOpen. 2014;3:897-909.

23. Boles BR, Horswill AR. Agr-mediated dispersal of Staphylococcus aureus biofilms. PLoS Pathog. 2008;4:e1000052.

24. Rohde H, Burdelski C, Bartscht K, Hussain M, Buck F, Horstkotte MA, et al. Induction of Staphylococcus epidermidis biofilm formation via proteolytic processing of the accumulation-associated protein by staphylococcal and host proteases. Mol Microbiol. 2005;55:1883-95.

25. Connelly MB, Young GM, Sloma A. Extracellular proteolytic activity plays a central role in swarming motility in Bacillus subtilis. J Bacteriol. 2004;186:4159-67.

26. Frank KL, Patel R. Poly-N-acetylglucosamine is not a major component of the extracellular matrix in biofilms formed by icaADBC-positive Staphylococcus lugdunensis isolates. Infect Immun. 2007;75:4728-42.

27. Missineo A, Di Poto A, Geoghegan JA, Rindi S, Heilbronner S, Gianotti V, et al. IsdC from Staphylococcus lugdunensis induces biofilm formation under low-iron growth conditions. Infect Immun. 2014;82:2448-59.

28. Nielsen VG, Losada PA. Direct Inhibitory Effects of Carbon Monoxide on Six Venoms Containing Fibrinogenolytic Metalloproteinases. Basic Clin Pharmacol Toxicol. 2017;120:207-12.

29. Lei F, Cui C, Zhao H, Tang X, Zhao M. Purification and characterization of a new neutral metalloprotease from marine Exiguobacterium sp. SWJS2. Biotechnol Appl Biochem. 2016;63:238-48. 
30. Hamada S, Kubota K, Sagisaka M. Purification and characterization of a novel extracellular neutral metalloprotease from Cerrena albocinnamomea. J Gen Appl Microbiol. 2017;63:51-7.

31. Rabinovich A, Mak IWY, Cowan RW, Turcotte RE, Colterjohn N, Singh G, et al. Matrix metalloproteinase activity in the stromal cell of giant cell tumor of bone. Open Bone J. 2009;1:46-52.

32. Arvidson S. Studies on extracellular proteolytic enzymes from Staphylococcus aureus. II. Isolation and characterization of an EDTA-sensitive protease. Biochim Biophys Acta. 1973;302:149-57.

33. Laarman AJ, Ruyken M, Malone CL, van Strijp JAG, Horswill AR, Rooijakkers SHM. Staphylococcus aureus metalloprotease aureolysin cleaves complement C3 to mediate immune evasion. J Immunol Baltim Md 1950. 2011;186:6445-53.

34. Pietrocola G, Nobile G, Rindi S, Speziale P. Staphylococcus aureus Manipulates Innate Immunity through Own and Host-Expressed Proteases. Front Cell Infect Microbiol. 2017;7. doi:10.3389/fcimb.2017.00166.

35. Elchinger P-H, Delattre C, Faure S, Roy O, Badel S, Bernardi T, et al. Effect of proteases against biofilms of Staphylococcus aureus and Staphylococcus epidermidis. Lett Appl Microbiol. 2014;59:507-13.

36. Abraham NM, Jefferson KK. Staphylococcus aureus clumping factor B mediates biofilm formation in the absence of calcium. Microbiology. 2012;158 Pt 6:1504-12. doi:10.1099/mic.0.057018-0.

37. Kobayashi K, Ikemoto Y. Biofilm-associated toxin and extracellular protease cooperatively suppress competitors in Bacillus subtilis biofilms. PLoS Genet. 2019;15:e1008232.

38. Pantaléon V, Soavelomandroso AP, Bouttier S, Briandet R, Roxas B, Chu M, et al. The Clostridium difficile Protease Cwp84 Modulates both Biofilm Formation and Cell-Surface Properties. PloS One. 2015;10:e0124971.

39. Damasco AP, Costa TM da, Morgado PGM, Guimarães LC, Cavalcante FS, Nouér SA, et al. Daptomycin and vancomycin non-susceptible methicillin-resistant Staphylococcus aureus clonal lineages from bloodstream infection in a Brazilian teaching hospital. Braz J Infect Dis. 2019;23:139-42.

40. Guimarães LC, Souza BM, Whitaker CO, Abreu F, Ferreira RBR, Dos Santos KRN. Increased biofilm formation by Staphylococcus aureus clinical isolates on surfaces covered with plasma proteins. J Med Microbiol. 2021.

41. Ferreira RBR, Ferreira MCS, Glatthardt T, Silvério MP, Chamon RC, Salgueiro VC, et al. Osmotic stress induces biofilm production by Staphylococcus epidermidis isolates from neonates. Diagn Microbiol Infect Dis. 2019;94:337-41.

42. Laemmli UK. Cleavage of structural proteins during the assembly of the head of bacteriophage T4. Nature. 1970;227:680-5.

43. Neuhoff V, Arold N, Taube D, Ehrhardt W. Improved staining of proteins in polyacrylamide gels including isoelectric focusing gels with clear background at nanogram sensitivity using Coomassie Brilliant Blue G-250 and R-250. Electrophoresis. 1988;9:255-62.

44. Shevchenko A, Wilm M, Vorm O, Mann M. Mass spectrometric sequencing of proteins silver-stained polyacrylamide gels. Anal Chem. 1996;68:850-8.

45. Rost B, Liu J. The PredictProtein server. Nucleic Acids Res. 2003;31:3300-4.

46. Shen H-B, Chou K-C. Gpos-mPLoc: a top-down approach to improve the quality of predicting subcellular localization of Gram-positive bacterial proteins. Protein Pept Lett. 2009;16:1478-84.

47. Yu NY, Wagner JR, Laird MR, Melli G, Rey S, Lo R, et al. PSORTb 3.0: improved protein subcellular localization prediction with refined localization subcategories and predictive capabilities for all prokaryotes. Bioinforma 
Oxf Engl. 2010;26:1608-15.

48. Yang J, Zhang Y. I-TASSER server: new development for protein structure and function predictions. Nucleic Acids Res. 2015;43:W174-181.

49. Stepanović S, Vuković D, Hola V, Di Bonaventura G, Djukić S, Cirković I, et al. Quantification of biofilm in microtiter plates: overview of testing conditions and practical recommendations for assessment of biofilm production by staphylococci. APMIS Acta Pathol Microbiol Immunol Scand. 2007;115:891-9.

\section{Figures}

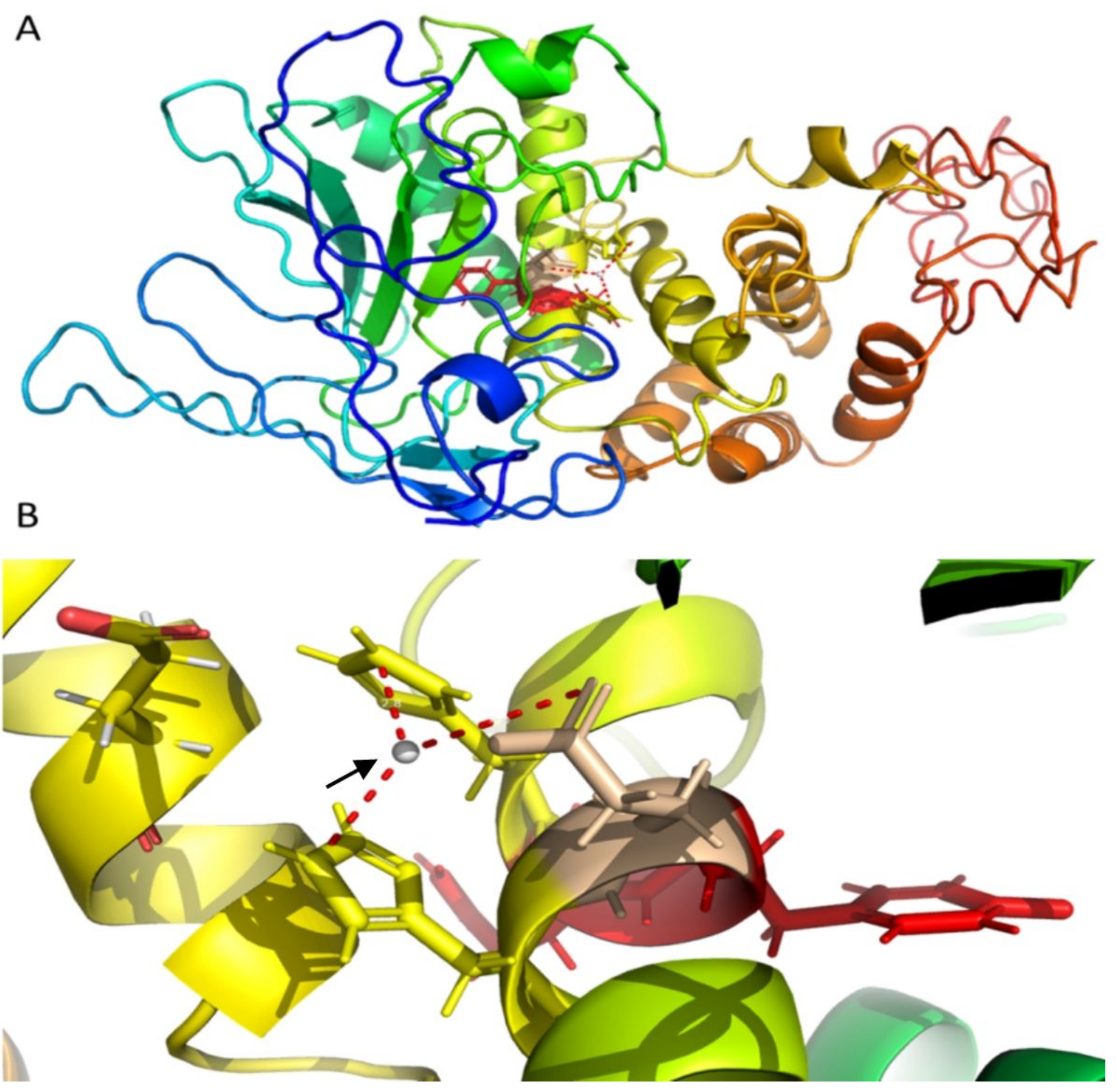

Figure 1 
Predicted 3D structure of the Staphylococcus lugdunensis neutral metalloprotease by I-TASSER homology modelling. TM-score = $0.44 \pm 0.14 ; \mathrm{RMSD}=12.5 \pm 4.3 \AA$. $\mathrm{HEXXH}(\mathrm{HEYQH})$ domain highlighted in red $(1 \mathrm{~A})$. Residues HIS241, HIS245 (highlighted in yellow) and GLU242 (highlighted in beige) are the catalytic triad, zoomed in Figure 1B. GLU268 was also highlighted as a yellow stick as it is a known catalytic residue conserved among M30 proteases. The catalytic zinc ion is represented by a grey sphere pointed by an arrow. The structure is C-a trace coloured according to sequence from dark blue ( $\mathrm{N}$ terminus) to red ( $\mathrm{C}$ terminus). Distances measured from the catalytic zinc to the catalytic amino acids were 2.8, 3.1 and $4.0 \AA$ for the residues HIS241, HIS245 and GLU268, respectively. Figures were drawn using PyMOL (www.pymol.org).

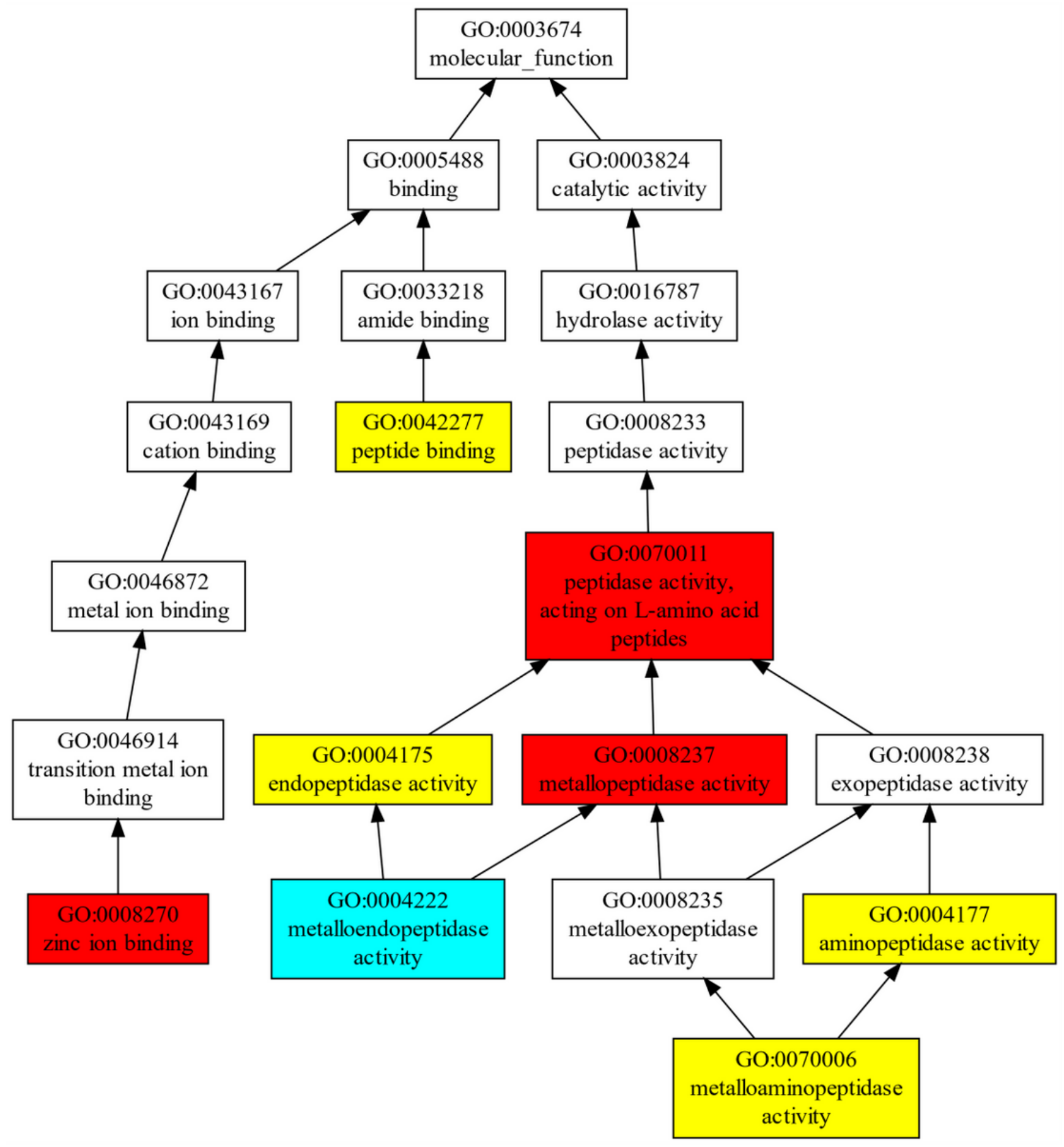

Figure 2 
Molecular functions of the lugdulysin metalloprotease determined by gene ontology via the Predict Protein database. The protease has two main domains, the HEXXH responsible for zinc (and other divalent ions) binding and the catalytic triad responsible for the peptidase activity. As per the highlighted boxes, the peptidase domain has aminopeptidase and endopeptidase activities, which are metal dependent. Moreover, the protease has also peptide binding capacity, which may be correlated with its activity.

A

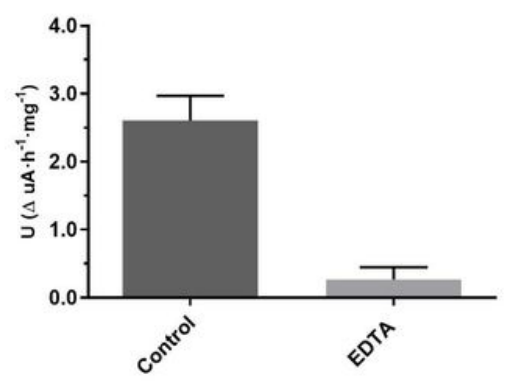

C

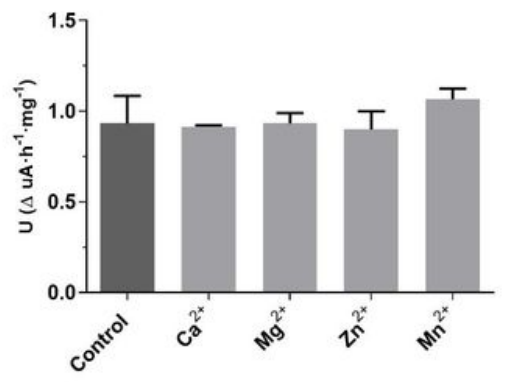

E

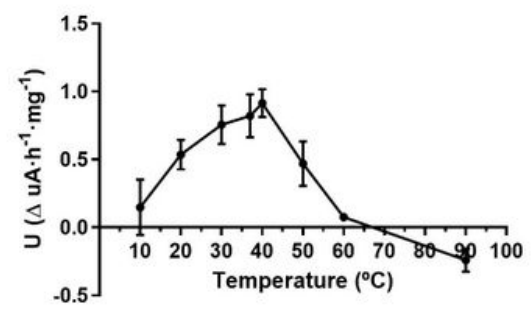

G

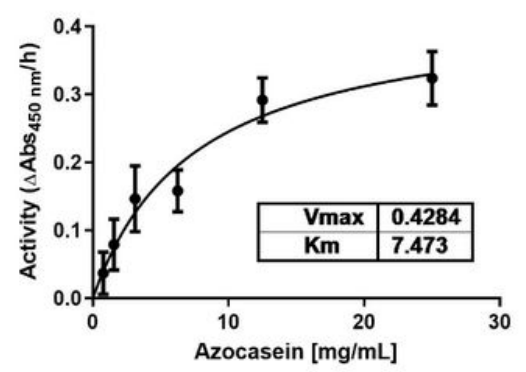

B

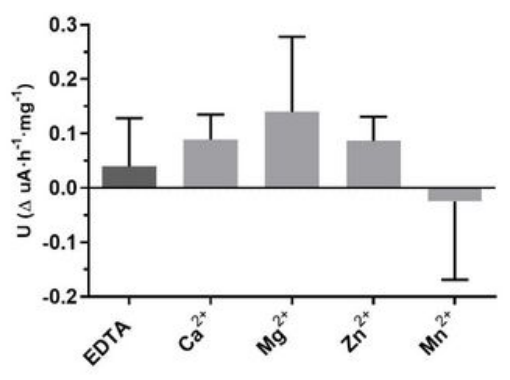

D

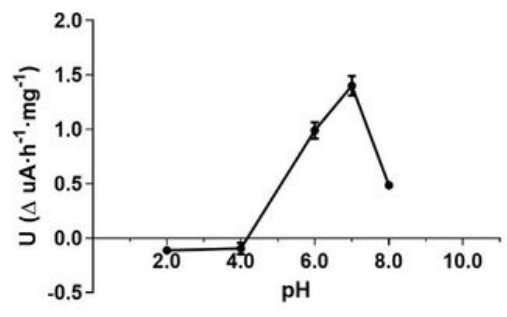

$\mathbf{F}$

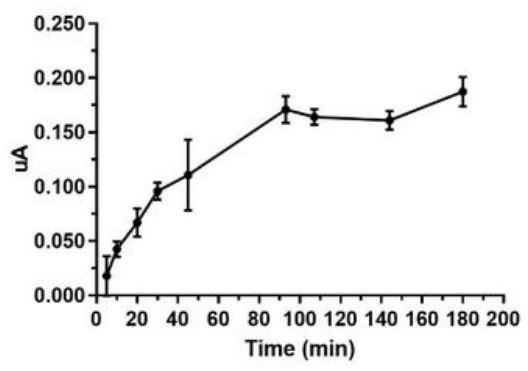

H

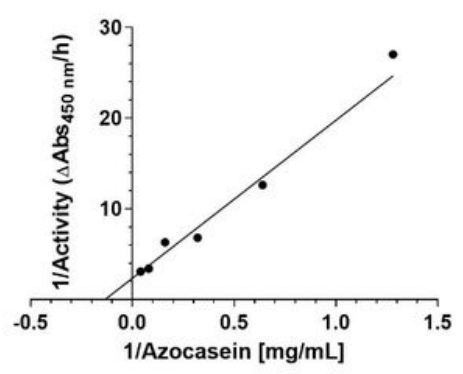

Figure 3

Aspects associated with the lugdulysin activity purified from Staphylococcus lugdunensis supernatant using azocasein as substrate. A) Inhibition of metalloprotease activity with EDTA $5 \mathrm{mM}$ (control = without EDTA) ( $p=$ 0.0045). B) Proteolytic activity recovery test with metallic ions supplementationCa2+, Mg2+, Zn2+or Mn2+. No 
significant difference was found in relation to EDTA inhibition $(p=0.9803,0.9530,0.9763$ and 0.9772

respectively). C) Effect in the enzymatic reaction by the addition of Ca2+, Mg2+, Zn2+orMn2+. Supplementation with metallic ions did not present significant difference when compared to no supplementation as control $(p=$ $0.9930,0.8772,0.9950$ and 0.1715 respectively). D) Optimal $\mathrm{pH}$ determination. The $\mathrm{X}$-axis represents the $\mathrm{pH}$ values tested, while $y$-axis shows the enzymatic activity in $U$. E) Determination of the optimal temperature conditions. X-axis represents temperature range used; $y$-axis shows the enzymatic activity in U. F) Enzymatic activity vs time. X-axis represents the timespan used; $y$-axis shows enzymatic activity in units of absorbance. G) Lugdulysin Michaelis-Menten constant determination. H) Double reciprocal Lineweaver-Burk graph.

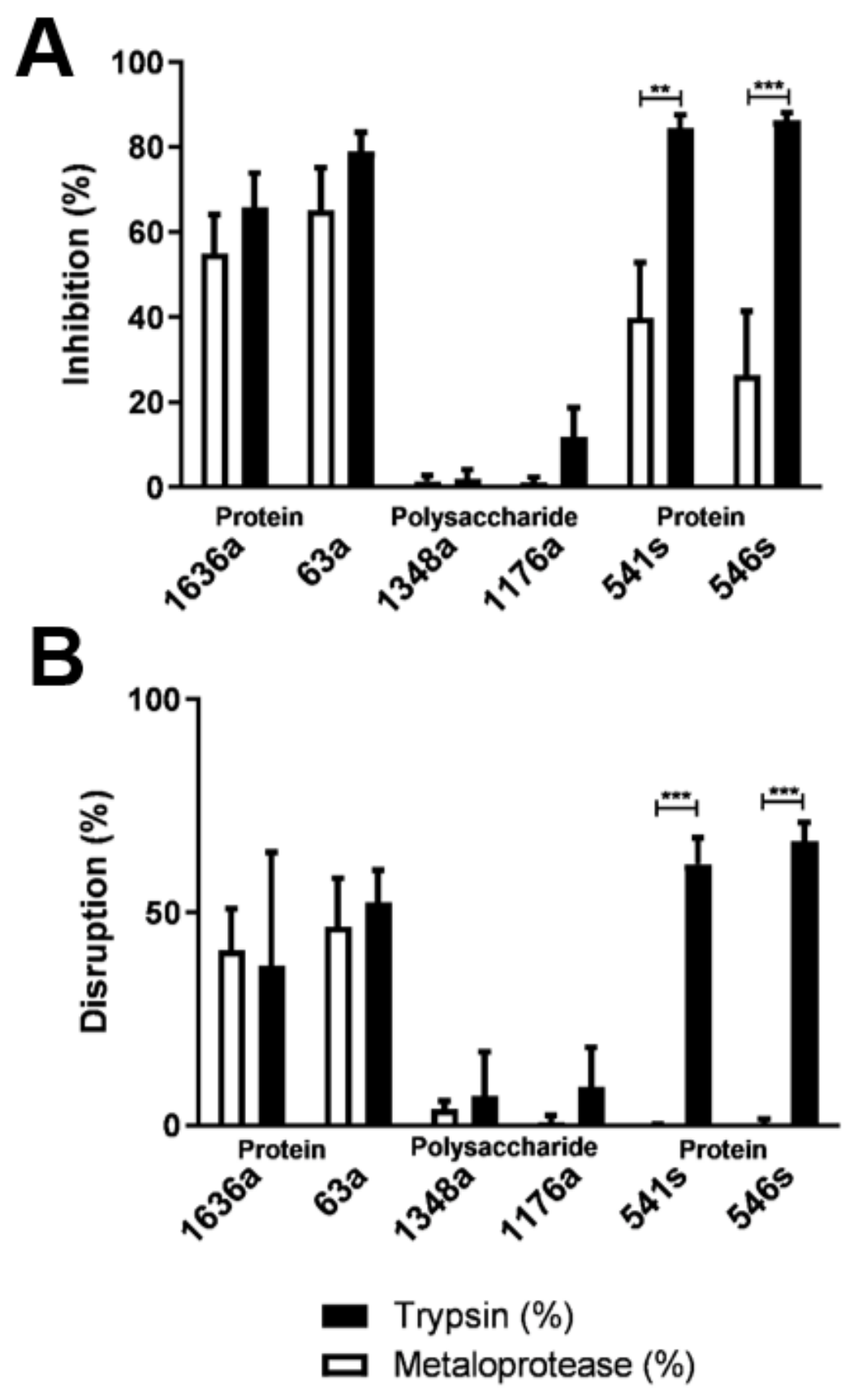

Figure 4

Influence of the lugdulysin or trypsin on S. aureus and S. lugdunensis biofilms. A) Effect of trypsin or lugdulysin non biofilm formation. Trypsin inhibited more than $70 \%$ of the S. lugdunensis protein biofilm (isolates $541 \mathrm{~s}$ and 
$546 \mathrm{~s}$ ) and between 60 and $70 \%$ of the $\mathrm{S}$. aureus protein biofilm (isolates $1636 \mathrm{a}$ and $63 \mathrm{a}$ ). There was less than $10 \%$ inhibition in polysaccharide biofilm (S. aureus isolates 1348a and 1176a). Lugdulysin metalloprotease showed reduction $>50 \%$ of S. aureus protein biofilm and between $20 \%$ and $40 \%$ of S. lugdunensis biofilm. B) Effect of trypsin or lugdulysin metalloprotease on disruption of pre-formed biofilm. Lugdulysin and trypsin showed similar effects on S. aureus biofilm (1636a and 63a isolates), with reduction from $40 \%$ to $50 \%$, and no biofilm reduction was found for S. lugdunensis biofilm when the lugdulysin was used. Trypsin inhibited more than $70 \%$ of S. lugdunensis protein biofilm (isolates 541s and 546s). Asterisks refer to comparison of treatment (lugdulysin or trypsin), with ** referring to the value of $p<0.001$ and $* \star \star$ as $p<0.0001$. 